Aletria, Belo Horizonte, v. 28, n. 1, p. 135-146, 2018

\title{
A crônica da cidade em "Macanudo", de Liniers: relações entre quadrinhos, literatura e jornalismo
}

\section{The chronicle of the city in "Macanudo", by Liniers: relations between comics, literature and journalism}

\author{
Jozefh Fernando Soares Queiroz \\ Universidade Federal de Alagoas, Maceió, Alagoas / Brasil \\ jozefh.f@gmail.com
}

Resumo: Esta análise apresenta um recorte específico das tiras do quadrinista argentino Ricardo Siri, conhecido como Liniers, que compõem a série "Macanudo", publicada desde 2002 nas páginas do jornal La Nación. Apesar da série se fundamentar em situações predominantemente humorísticas, nesta seleção se pretende mostrar os diálogos existentes entre as tiras de jornal e as notícias nele veiculadas, sob o olhar crítico do autor, que exerce um posicionamento por vezes divergente daquele que figura na grande mídia. Para entender o funcionamento desta forma narrativa, que atrela quadrinhos, literatura e jornalismo, são analisadas quatro tiras do autor, dialogando com teóricos destes três campos específicos, a exemplo de Antonio Candido (1980), Florencia Levin (2015), Josefina Ludmer (2013), Martín Caparrós (2012) e Oscar Masotta (2010).

Palavras-chave: Macanudo; Liniers; quadrinhos; literatura; jornalismo; crônica.

Abstract: This analysis presents a specific clipping of the comic strips by Argentine
comics artist Ricardo Siri, known as Liniers, that compose the series "Macanudo",
published since 2002 in the pages of the newspaper La Nación. Although the series is
predominantly based on humoristic situations, this selection intends to show the existing
dialogues between the newspaper strips and the news it reports, under the critical eye of
the author who has a point of view that is sometimes divergent from the one exposed by
the mainstream media. In order to understand how this narrative form functions, which
links comics, literature, and journalism, four strips by the author are analyzed, in dialogue
with theorists of these three specific fields, such as Antonio Candido (1980), Florencia
Levin(2015), Josefina Ludmer (2013), Martín Caparrós (2012), and Oscar Masotta (2010). Keywords: Macanudo; Liniers; comics; literature; journalism; chronicle. 


\section{Introdução}

Desde 2002, todos os dias os leitores do jornal argentino La Nación têm a oportunidade de adentrar o universo de Ricardo Siri (Liniers) por meio da sua tira cômica "Macanudo". Na série, que reúne diferentes universos interdependentes, o autor escolhe a cada tira, de maneira aleatória, qual personagem protagonizará cada trama. "Macanudo" já rende, até o momento, aproximadamente quatro mil tiras publicadas, compiladas em 13 volumes e traduzida em países como o Brasil, Canadá, França, Estados Unidos, Itália e República Checa.

Esta leitura de Liniers pretende abordar um recorte bastante específico de suas tiras, aquele que mais se aproxima da literatura ao pensarmos no gênero crônica e compará-lo com os quadrinhos, seja pela forma em que se apresenta ou em relação às suas condições de produção, ainda que nos distanciemos do humor típico do artista. $\mathrm{O}$ aspecto de crônica que seus quadrinhos assumem se manifesta em "Macanudo" devido a dois elementos, o primeiro deles graças à referência a acontecimentos pontuais vivenciados pela sociedade local e global, e o segundo, devido à agilidade em retratar tais eventos em razão da dinâmica da publicação, num ritmo quase diário, nos jornais e na internet.

\section{O quadrinho-crônica de Liniers}

Se em várias outras de suas tiras Liniers utiliza um humor fundamentalmente abstrato, nonsense e fantasioso, elementos predominantes em sua obra, esta faceta de suas tiras aqui abordada se pauta na ligação direta entre o quadrinho e o mundo real do leitor e autor, na composição da narrativa gráfica como registro de acontecimentos urbanos, evidenciando uma íntima ligação entre as histórias em quadrinhos, a crônica e o caráter informativo dos jornais que as narrativas gráficas assumem. Neste processo, destaca-se a memória da cidade como elo entre estas formas narrativas. Além disso, trata-se de uma faceta fundamentalmente intertextual da obra, já que dialoga tanto com acontecimentos presentes na vida do leitor quanto com o gênero crônica, estreitando as relações entre quadrinhos e história, ao mostrar um posicionamento político e ideológico do autor frente a alguns acontecimentos, ${ }^{1}$ por meio de uma publicação diária.

\footnotetext{
${ }^{1}$ MASOTTA. Consciencia y estructura, p. 270.
} 
Além da sobreposição entre quadrinhos, literatura e jornalismo, este estudo aponta, em maior ou menor escala, uma certa subversão da linguagem dos quadrinhos; outrora utilizados para representar situações improváveis em nosso cotidiano, como a presença de super-heróis e outros elementos fantásticos. Neste recorte, as narrativas se apresentam como um documentário e registro das ações ocorridas no espaço urbano, ressignificando sua linguagem e ampliando sua capacidade narrativa. Esta aglutinação das características da crônica é um movimento natural, segundo Ludmer, visando inaugurar novas formas de narrar:

Suponhamos que o mundo mudou e que estamos em outra etapa da nação, outra configuração do capitalismo e outra era na história dos impérios. Para poder entender esse novo mundo (e escrevê-lo como testemunho, documentário, memória e ficção), precisamos de um aparato diferente daquele que usávamos antes. Outras palavras e conceitos, porque não é apenas o mundo que mudou, mas também os modelos, gêneros e espécies nos quais ele se dividia e se diferenciava. ${ }^{2}$

Ludmer nos convida a imaginar o mundo como tempo, e no espaço urbano as suas mudanças e movimentos dinâmicos requerem outras formas de registro e narração anteriormente desconhecidos ou simplesmente inexplorados. Se há cada vez mais pluralidade nas relações humanas, as ferramentas de registro e captação vigentes desses elementos podem passar a ser insuficientes para apreendê-los.

Desta forma, os quadrinhos passam a aglutinar características de outros gêneros, como a crônica e o caráter informativo do jornal, para simular seus efeitos de sentido, ampliando seu potencial narrativo. Por meio da análise de alguns desses registros, percebe-se que ao remeter à realidade do público não há uma perda da capacidade imaginativa do autor ou de elementos humorísticos, como se pode ver em uma das tiras do autor publicada no ano de 2010, em que remetia a uma preocupante epidemia que afetava a Argentina e outros países. ${ }^{3}$

\footnotetext{
${ }^{2}$ LUDMER. Aqui América Latina, p. 7.

${ }^{3}$ Cf. a primeira tira de: EL ARTE de Liniers 2.0 (click para ampliar). Disponível em: $<$ http://leandrobartoletti.blogspot.com.br/2011/05/el-arte-de-liniers-20-click-para. html >. A tira pode também ser vista em: LINIERS. Macanudo, p. 16.
} 
Apesar da publicação independente, a tira não é autocontida. Dotada de elementos fantásticos, como a presença de animais realizando ações humanas, além do fato de refletirem sobre o seu lugar na sociedade e pela execução de um plano de vingança, a tira convoca o repertório de experiências prévias do leitor para que possa ter sentido. O humor reside na referência ao vírus Influenza A, ou H1N1, popularmente conhecido como gripe suína. Seu surto mais reportado na mídia ocorreu no México no ano de 2009, pouco antes da publicação da tira, espalhando-se para outros países como Estados Unidos, Canadá e a própria Argentina, que à época noticiava massivamente os novos casos da doença descobertos no país.

$\mathrm{O}$ autor articula uma de suas ferramentas narrativas mais recorrentes, a presença de animais que atuam como seres humanos, a dois elementos intrínsecos à realidade do leitor: o termo com o qual as pessoas passaram a se referir comumente ao vírus e o estado de pânico que vivenciaram no momento da pandemia. $\mathrm{O}$ que anteriormente seria apenas uma tira cômica, com sentido próprio, passa a exercer uma estreita ligação com o cotidiano do leitor, sendo exigido deste um repertório específico de experiências para compreender a sátira. Ao ser publicado diariamente no jornal, ao lado de outras notícias, o quadrinho pode também assumir este caráter jornalístico, esperando que os seus leitores utilizem o repertório de informações adquiridas no periódico para compreender a narrativa.

$\mathrm{O}$ mesmo fenômeno ocorre em outra tira, publicada alguns anos depois, também realizada a partir da articulação de elementos externos à narrativa gráfica e intrínsecos à realidade dos leitores, ${ }^{4}$ especialmente aqueles que acompanham as notícias. Publicada originalmente no dia 6 de agosto de 2014, o trabalho do autor simboliza uma sutil homenagem à Estela de Carlotto, ${ }^{5}$ líder das Avós da Praça de Maio, grupo de mulheres ativistas que buscam encontrar seus filhos, netos e demais familiares sequestrados e desaparecidos no período da ditadura militar argentina, ocorrida entre os anos de 1966 e 1973. No dia anterior à sua publicação, o neto da então líder do grupo, Ignacio Carlotto, mais conhecido como Guido, havia sido encontrado após 35 anos de intensas buscas e forte

\footnotetext{
${ }^{4}$ Cf. LINIERS. Carlotto y nieto 114. Disponível em: $<$ https://s-media-cache-ak0.pinimg. com/originals/b0/86/2d/b0862d6cc6bf608421f15fd12b90c8a5.jpg >.

${ }^{5}$ Para mais informações sobre o caso, cf.: ESTELA de Carlotto encontró a su nieto, Guido, tras 36 años de búsqueda.
} 
ativismo por parte da líder Carlotto, o que gerou comoção pública em todo o território nacional, dado o reconhecimento de seu trabalho.

Liniers presta sua homenagem à ativista por meio da narrativa gráfica, publicada um dia após a divulgação do ocorrido, destituindose do seu costumeiro humor para assumir o caráter de uma crônica política. Sem adentrar nas feridas ainda não cicatrizadas, provocadas pela sanguinária ditadura argentina, o autor, num gesto metonímico, acaba por ressaltar toda a importância da militância liderada à época por Carlotto, representando em sua narrativa gráfica um dos frutos colhidos pela batalha que vem se prolongando por décadas. Ao mencionar essa discrição com a qual a crônica se dirige a temas de grande seriedade, Candido afirma que "ela se ajusta à sensibilidade de todo o dia. Principalmente porque elabora uma linguagem que fala de perto ao nosso modo de ser mais natural. Na sua despretensão, humaniza." 6

Este recurso narrativo vem sendo explorado com maior ênfase por Liniers nos anos mais recentes de sua produção, advindos da consolidação do trabalho realizado em "Macanudo" e pela possibilidade de imprimir à série um tipo de mensagem fortemente marcada pela autoria e indissoluvelmente ligado ao contexto informativo do jornal. ${ }^{7}$

Já no início de 2015, pelo menos dois casos significativos a nível nacional e mundial foram "capturados" pelo autor em forma de narrativa gráfica e publicados como uma suposta crônica em quadrinhos. O primeiro deles remete sutilmente às ações do governo argentino, então comandado pela presidenta Cristina Kirchner, diante de uma grave crise política com a qual seu governo se envolveu no início desse ano, cujos desdobramentos são retratados em uma narrativa que aparentemente simula outra ação corriqueira. ${ }^{8}$

O humor existente na sátira reside no fato de que os fantasmas que atormentam as crianças já não são figuras abjetas que constituem o imaginário infantil, mas os elementos intrínsecos ao seu cotidiano, como a menção a um órgão investigativo do governo. A referência à Secretaria de Inteligência remete ao assassinato do promotor argentino Alberto Nisman, encontrado morto em seu apartamento no dia 19 de janeiro de

\footnotetext{
${ }^{6}$ CANDIDO. A vida ao rés-do-chão, p. 13.

${ }^{7}$ LEVIN. Humor gráfico, p. 77.

${ }^{8}$ Cf. MACANUDO del día 24-01-2015. Disponível em: <http://einblauergeist.tumblr. com/post/109030290950/macanudo-del-d\%C3\%ADa-24-01-2015>.
} 
2015. Anteriormente, Nisman denunciara a então presidente por, em troca de favores políticos, encobrir o Irã em atos terroristas ocorridos em 1994.

Realizadas as primeiras investigações oficiais, a Secretaria de Inteligência chegou à insatisfatória conclusão, para a opinião popular, de que o promotor havia cometido suicídio, mesmo que houvesse várias provas em contrário. $\mathrm{O}$ autor se apropria da repercussão do caso para incorporá-lo ao seu repertório humorístico, nivelando aqueles que compõem tal secretaria ao patamar de outras criaturas horrendas, como forma de manifestar, por meio da narrativa gráfica, a sua desconfiança com as declarações do governo, dado que houve a suspeita de assassinato motivado por queima de arquivo e o consequente acobertamento do crime por parte do órgão. Desta forma, o autor se posiciona de maneira cética às declarações do governo, sem deixar de lado o seu costumeiro humor que reside no seu universo de personagens gráficos.

Outro caso de grande projeção internacional foi o atentado terrorista ocorrido em Paris no dia 7 de janeiro do mesmo ano, 2015, na sede do jornal humorístico Charlie Hebdo, que anteriormente havia publicado uma caricatura do profeta Maomé e despertara a ira de grupos extremistas islâmicos. Na ocasião, pelo menos 23 pessoas foram atingidas, chegando ao saldo de 12 mortos. ${ }^{9}$ Milhares de pessoas ao redor do mundo manifestaram nas principais redes sociais seu apoio aos integrantes do periódico com a frase "Je suis Charlie" ('Eu sou Charlie'), que se tornou um slogan reivindicatório da liberdade de expressão. No entanto, o autor se utiliza desse contexto para elaborar seu quadrinhocrônica a respeito de outro atentado ocorrido posteriormente, motivado pela ausência de destaque nos jornais sobre o fato a seguir. ${ }^{10}$

Desta vez, a tira à qual se faz menção no momento mostra que o autor se apropria do simbolismo da frase gerada a partir do incidente ocorrido na França para rememorar outro atentado de proporções ainda maiores, obliterado pelos grandes meio de comunicação: o ataque terrorista realizado pelo grupo Al Shebab, composto por islamitas somalianos, contra estudantes da Universidade de Garissa, no Quênia,

\footnotetext{
${ }^{9}$ Para mais informações sobre o caso, cf.: ATAQUE em sede do jornal Charlie Hebdo em Paris deixa mortos.

${ }^{10}$ Cf. LINIERS. [Je suis]. Disponível em: <https://br.pinterest.com/pin/ 437271445046988681/>.
} 
que resultou em 148 mortos. ${ }^{11}$ Três meses após o incidente ocorrido em Paris e sua grande comoção mundial, o incidente ocorrido no continente africano, que deixou um número quase treze vezes maior de mortos, recebeu projeção na mídia infinitamente menor que o atentado de janeiro.

Por meio dos quadrinhos, e também graças à sua proximidade com o jornal, Liniers registra o incidente de forma irônica, questionando a ausência daquela comoção outrora direcionada aos franceses, revestido de um tom acusatório sobre como a mídia pode ser parcial de acordo com os seus interesses. Além de convidar o leitor a refletir sobre ambos os acontecimentos e a respectiva atenção dada a cada um deles, a tira se apresenta como registro de um fato e resgate da memória, preservando, por meio de sua acuidade crítica, a homenagem prestada às vítimas do atentado anteriormente ofuscado pela mídia. Trata-se de um gesto político, como Caparrós defende ao mencionar que "[a] crônica é uma forma de nos determos ante a informação e sua política do mundo: é uma maneira de dizer que o mundo também pode ser outro. A crônica é política". ${ }^{12}$

Curiosamente, à exceção da primeira das tiras apresentadas, as três seguintes nunca foram compiladas em livro, o que ocorre geralmente todos os anos e projeta o autor para um público mais amplo, além daquele do jornal, e também internacionalmente. Tal decisão editorial, ainda que escape do alcance desta análise, pode ser justificada exatamente graças a este caráter informativo das tiras, que, uma vez transpostas para uma mídia atemporal como o livro, perderiam o seu caráter jornalístico. Desta forma, é possível reforçar o caráter de crônica dos quadrinhos devido à sua existência subsistir fundamentalmente no jornal, lado a lado com as notícias.

Desta forma, as tiras se apresentam não apenas como possibilidade de apreensão da memória, mas também como reflexão sobre a experiência vivenciada: até que ponto realmente podemos sentir a dimensão do atentado ocorrido e para onde direcionamos o nosso luto? A este respeito, Manguel afirma que

\footnotetext{
${ }^{11}$ Para informações sobre o caso, cf:: ATAQUE a cristãos em universidade no Quênia deixa ao menos 148 mortos.

12 "la crónica es una forma de pararse frente a la información y su política del mundo: una manera de decir que el mundo también puede ser otro. La crónica es política" (CAPARRÓS. Por la crónica, p. 610, tradução minha).
} 
A memória, no Ocidente, é o vínculo da nossa experiência, ao longo da linha do tempo, com os repositórios do passado. Em termos inúteis, a memória equivale em tudo à experiência presente: aquilo que é lembrado é a realidade em que vivemos, física e imaginativamente. Não há "graus" de conhecimento ou reconhecimento no ato de rememorar. Somos aquilo que a experiência prévia nos ensinou como indivíduos ou como comunidades - mas, para sermos mais exatos, teríamos de dispensar o termo "prévia". A história que foi contada existe apenas como a história que está sendo contada agora. ${ }^{13}$

Nestes termos, a crônica apresentada por meio da narrativa gráfica não apenas presta uma homenagem às dezenas de vítimas do atentado em questão, mas convida o público a rememorar os eventos ocorridos e repensar a sua noção de experiência diante do fato. Repensá-lo, por meio do quadrinho-crônica, permite ao leitor não apenas revisitar esses repositórios do passado, nas palavras de Manguel, mas evocar o aprendizado que a experiência diante do assunto nos traz. Ainda em suas palavras,

Por impalpáveis que sejam, nossas linguagens nos dão o poder de impor alguma ordem ao mundo; é por meio de histórias contadas e recontadas que constituímos nossas identidades. Por fim, é nas palavras da literatura que traduzimos o melhor de nosso esforço para imaginar a vida em comum. ${ }^{14}$

Os estudos literários já não se debruçam, na atualidade, sobre a missão de definir o que é ou não literatura: as fronteiras entre a linguagem literária e outras formas de narrar tem sido cada vez mais aproximadas, visando inaugurar novas maneiras de contar histórias, por meio de uma simbiose dessas linguagens. As narrativas gráficas, em sua linguagem multifacetada e ágil, ligadas ao dinamismo da publicação do jornal, permitem estabelecer algumas destas novas possibilidades narrativas. Não é de se estranhar, devido ao potencial das imagens, a sua capacidade de abstrair-se da realidade e, em dados momentos, apropriar-se da mesma e mimetizar o gênero crônica, ampliando o leque de possibilidades existentes para registrar nossa história e nossa identidade. No entanto,

\footnotetext{
${ }^{13}$ MANGUEL. A cidade das palavras, p. 79.

${ }^{14}$ MANGUEL. A cidade das palavras, texto de orelha.
} 
é de fundamental importância a proximidade com o leitor para realizar essa operação:

As cidades cada vez se mostram como as grandes protagonistas do quadrinho documental e os seus autores-personagens como personagens secundários, ajudam a conduzir essa narrativa nas páginas. O leitor, rompendo a quarta parede, vive o texto e vive as sensações e os estranhamentos do autor, antropólogo do quadrinho documental. O leitor garimpa o texto e traduz, também ao seu modo, a cidade - é quando chegamos o mais perto da sua transcriação. ${ }^{15}$

Assim sendo, a elaboração do quadrinho-crônica, que documenta o posicionamento de Liniers frente a acontecimentos relevantes do mundo, ainda que minimizados pela grande mídia em alguns casos, somente pode se tornar possível quando o leitor compartilhar do horizonte de expectativas do autor, que se utilizará da massividade do público estabelecido pelo jornal para se manifestar e atingi-lo, chamando sua atenção para os eventos captados.

Convém destacar, ademais, que a rapidez com a qual o autor se reporta às situações aqui utilizadas como referência se deve não apenas ao caráter informativo do jornal, mas também à internet: se os meios de elaborar a crônica se metamorfosearam com o passar dos anos, é natural que as formas de produção e circulação dessas narrativas também tenham se modificado. O suporte da crônica, outrora apenas físico, adquire agilidade por meio do mundo virtual, de maneira a acompanhar a velocidade com a qual se veiculam as notícias na internet, a partir das quais se elaboram as "tirinhas-crônica", facilitando ao leitor a associação dos eventos articulados no plano da narrativa gráfica.

Além de Liniers, diversos quadrinistas de renome se utilizam das redes sociais para fazer circular suas tiras, que refletem sobre eventos pontuais, a exemplo de Laerte e André Dahmer, no Brasil. Porém, este fenômeno tem se fortalecido na Argentina no decorrer da história, devido a características específicas do mercado de quadrinhos nesse país, intimamente ligados a condições socioeconômicas:

${ }^{15}$ MUANIS. O quadrinho documental e a tradução da cidade, p. 56-57. 
A digitalização das comunicações, a internet e o e-mail - depois as redes sociais - facilitaram o trabalho à distância, trabalho ao qual se incorporarão muitos desenhistas biologicamente mais jovens, mas geracionalmente ligados a uma geração formada na indústria. [...] O desaparecimento da tradicional indústria editorial de quadrinhos na Argentina é parte significativa das condições possíveis de produção e edição independentes e de distribuição alternativa. ${ }^{16}$

\section{Considerações finais}

Neste sentido, há de se considerar que as fortes marcas de autoria presentes na crônica existente nos quadrinhos são oriundas de uma nova estratégia de desenvolvimento ao qual se submeteram os quadrinhos argentinos por um longo período, devido à necessidade de se tornarem mais independentes do mercado editorial, graças à sua controversa situação econômica no decorrer do tempo, permitindo-lhe assumir novas estratégias discursivas como forma de interpelar ao público.

O contexto socioeconômico, aliado ao desenvolvimento da tecnologia e à velocidade com que circulam as notícias foi fundamental para o crescimento da crônica presente nos quadrinhos, uma tendência comum aos autores que utilizam o seu trabalho para realizar leituras da sociedade na qual estão inseridos. Aliados ao seu potencial imagético, as narrativas gráficas nos mostram, em poucos exemplos, a sua capacidade de aglutinar elementos literários e jornalísticos, evidenciando o seu potencial não apenas informativo, mas também narrativo, efeitos múltiplos característicos de um gênero híbrido como este.

\footnotetext{
16 "La digitalización de las comunicaciones, Internet y el correo electrónico - luego las redes sociales - facilitaron el trabajo a distancia, trabajo en el cual también se involucrarán muchos dibujantes biológicamente más jóvenes pero generacionalmente ligados a la generación formada en la industria. [...] La desaparición de la tradicional industria editorial argentina de historietas es parte significativa de las condiciones de posibilidad y de producción de autoediciones independientes y distribución alternativa" (VON SPRECHER; RODRÍGUEZ. Digitalización. Los blogs de historietas, p. 220, tradução minha).
} 


\section{Referências}

ATAQUE a cristãos em universidade no Quênia deixa ao menos 148 mortos. Folha de S. Paulo, São Paulo, 2 abr. 2015, 8 h 5 min.; atual. 4 abr. 2015, 7 h 59 min. Mundo. Disponível em: <http://www1.folha.uol. com.br/mundo/2015/04/1611625-ataque-de-milicia-a-universidade-noquenia-deixa-15-mortos.shtml>. Acesso em: 26 out. 2017.

ATAQUE em sede do jornal Charlie Hebdo em Paris deixa mortos. G1, São Paulo, 7 jan. 2015, 9 h 21 min.; atual. 8 jan. 2015, 20 h 57 min. Disponível em: $<$ http://g1.globo.com/mundo/noticia/2015/01/tiroteiodeixa-vitimas-em-paris.html>. Acesso em: 26 out. 2017.

CANDIDO, Antonio. A vida ao rés-do-chão. In: COUTINHO, Fernanda; CARVALHO, Marília; MOREIRA, Renata (Org.). A vida ao rés-do-chão: artes de Bispo do Rosário. Rio de Janeiro: 7Letras, 1980. p. 13-22.

CAPARRÓS, Martín. Por la crónica. In: AGUDELO, Darío Jaramillo (Org.). Antología de crónica latinoamericana actual. México, DF: Alfaguara, 2012. p. 607-612.

EL ARTE de Liniers 2.0 (click para ampliar). Enter Miraski On Line, 19 mayo 2011, 17 h 29 min. Publicado por Leandro Bartoletti. Disponível em: $<$ http://leandrobartoletti.blogspot.com.br/2011/05/el-arte-de-liniers20-click-para.html>. Acesso em: 27 fev. 2018.

ESTELA de Carlotto encontró a su nieto, Guido, tras 36 años de búsqueda. La Nación, [Buenos Aires], 5 ago. 2014, 10 h18 min. Política. Disponível em: $<$ http://www.lanacion.com.ar/1715975-estela-de-carlotto-recuperoa-su-nieto-guido-tras-35-anos-de-busqueda > Acesso em: 26 out. 2017.

LEVIN, Florencia. Humor gráfico: manual de uso para la historia. Los Polvorines: Universidad Nacional de General Sarmiento, 2015.

LINIERS. [Je suis]. Publicado no Pinterest por macanudo.com.ar. [s.d.]. Disponível em: <https://br.pinterest.com/pin/437271445046988681/>. Acesso em: 27 fev. 2018.

LINIERS. Carlotto y nieto 114. Publicado no Pinterest por mvr. [s.d.]. Disponível em: < https://s-media-cache-ak0.pinimg.com/originals/ b0/86/2d/b0862d6cc6bf608421f15fd12b90c8a5.jpg>. Acesso em: 27 fev. 2018. 
LINIERS. Macanudo. Buenos Aires: Editorial Común, 2010. v. 8.

LUDMER, Josefina. Aqui América Latina. Tradução de Rômulo Monte Alto. Belo Horizonte: Editora UFMG, 2013.

MACANUDO del día 24-01-2015. Publicado no Tumblr por einblauergeist, 24 enero 2015. Disponível em: <http://einblauergeist.tumblr.com/ post/109030290950/macanudo-del-d\%C3\%ADa-24-01-2015>. Acesso em: 27 fev. 2018.

MANGUEL, Alberto. A cidade das palavras: as histórias que contamos para saber quem somos. Tradução de Samuel Titan Jr. São Paulo: Companhia das Letras, 2008.

MASOTTA, Oscar. Consciencia y estructura. Buenos Aires: Eterna Cadencia, 2010.

MUANIS, Felipe. O quadrinho documental e a tradução da cidade. Revista Nona Arte, São Paulo, v. 2, n. 1, p. 45-57, jan.-jun. 2013.

POR LINIERS. Disponível em: <www.porliniers.com>. Acesso em: 26 out. 2017.

VON SPRECHER, Roberto; RODRÍGUEZ, José. Digitalización. Los blogs de historietas. El caso de "Historietas reales". In: BAETENS, Jan et al. La historieta. Coordenação de Oscar Steimberg. Buenos Aires: Instituto Universitario Nacional del Arte; Rosario: UNR Editora, Editorial de la Universidad Nacional de Rosario, 2015. p. 215-224. (DeSignis / Lucrecia Escudero Chauvel).

Recebido em: $1^{\circ}$ de novembro de 2017. Aprovado em: $1^{\circ}$ de março de 2018. 